\title{
David HEMPTON, Hugh MCLEOD (eds.), Secularization and Religious Innovation in the North Atlantic
} World

Oxford-New York, Oxford University Press, 2017, 407 p.

Jean-Pierre Bastian

\section{OpenEdition}

\section{Journals}

Édition électronique

URL : https://journals.openedition.org/assr/44930

DOI : $10.4000 /$ assr.44930

ISSN : $1777-5825$

Éditeur

Éditions de l'EHESS

Édition imprimée

Date de publication : 1 décembre 2018

Pagination : 302-303

ISSN : 0335-5985

Référence électronique

Jean-Pierre Bastian, « David hempton, Hugh mcLeod (eds.), Secularization and Religious Innovation in the North Atlantic World », Archives de sciences sociales des religions [En ligne], 184 | octobre-décembre 2018, mis en ligne le 01 décembre 2018, consulté le 11 janvier 2022. URL : http:// journals.openedition.org/assr/44930 ; DOI : https://doi.org/10.4000/assr.44930

Ce document a été généré automatiquement le 11 janvier 2022.

(c) Archives de sciences sociales des religions 


\section{David HEMPTON, Hugh MCLEOD (eds.), Secularization and Religious Innovation in the North Atlantic World}

Oxford-New York, Oxford University Press, 2017, 407 p.

Jean-Pierre Bastian

\section{RÉFÉRENCE}

David HEMPTON, Hugh MCLEOD (eds.), Secularization and Religious Innovation in the North Atlantic World, Oxford-New York, Oxford University Press, 2017, 407 p.

1 Fruit d'un workshop mené à l'Université de Harvard en 2013 et 2014, seize contributeurs sous la coordination de deux experts en la matière abordent l'approche comparée de la sécularisation entre États-Unis et Europe de l'Ouest sous l'angle de l'innovation religieuse et dans une perspective plus historique que sociologique. Discussion classique dans la sociologie des religions des années 1960, où le maintien des pratiques et de la place des institutions religieuses dans le paysage social et politique nordaméricain interrogeait le décrochage religieux européen comme modèle d'interprétation. Des sociologues comme Peter Berger y répondaient en mettant en avant la sécularisation interne aux organisations religieuses américaines qui fonctionnaient comme des instances de marketing religieux. D'autres, avançant l'idée de "sécularisations multiples ", soulignaient l'exception européenne en la matière qui ne pouvait être qu'un modèle d'interprétation parmi d'autres.

Constatant cependant la faiblesse de la perspective historique dans le débat sociologique, l'ouvrage vise à revoir la question en introduisant des éléments d'analyse et met l'accent non tant sur les différences entre l'un et l'autre côté de l'Atlantique que sur leurs ressemblances. Sans pouvoir rendre compte de toutes les contributions, 
signalons qu'elles sont organisées deux par deux autour de huit analyseurs : le trinôme Église-État-argent, l'évangélisme, les religions nées aux États-Unis, le genre, la culture populaire, la Seconde Guerre mondiale et le réveil religieux qui suivit, Vatican II et l'évolution catholique, les années 1970. Parmi les essais rassemblés, Stewart J. Brown lance le débat et aborde le processus de sécularisation dans la Grande-Bretagne impériale de 1830 à 1930, remettant d'emblée en question l'approche de la théorie dite du choix rationnel qui soutient que l'absence de compétition tendrait à la stagnation, voire au déclin religieux. Il défend l'idée que la religion britannique organisée ne cessa de mettre en œuvre des formes innovantes de pastorale et d'engagement social, entre autres; David Bebbington montre, pour sa part, que jusqu'à la fin du XIX ${ }^{e}$ siècle, les évangélismes américain et britannique se développèrent de manière similaire. Heather Curtis, dans un essai sur les médias évangéliques, souligne la capacité innovante américaine contribuant à la vitalité du protestantisme. Dans une perspective d'étude de genre, Ann Braude analyse « l'Union de femmes chrétiennes pour la tempérance » : elle soutient qu'elle fut une vigoureuse organisation de renforcement de la religiosité américaine, mais en tant que mouvement de défense des droits des femmes, elle rencontra une vive opposition au sein même des églises. Comparant les pentecôtismes britannique et américain, Randall Stephens explique la plus intense mobilisation du second par sa meilleure capacité à assimiler la musique populaire. Un autre rapport à la culture populaire est celui de la religion au sport. Dans une synthèse originale, Hugh Mcleod aborde la dynamique religieuse de cette muscular christianity, qui prit son essor dès la fin du XIX $x^{e}$ siècle des deux côtés de l'Atlantique. Par ailleurs, le catholicisme américain est mis en perspective avec le catholicisme allemand par Wilhelm Damberg, avançant que l'impact des évolutions sociétales commença plus tôt et fut plus rapide en Allemagne.

3 Autre phénomène religieux contemporain, la montée en force des mega churches fut une expression religieuse nord-américaine exportée de manière très limitée en Europe selon Kip Richardson pour lequel la vigueur de l'évangélisme américain explique la différence entre les deux espaces. De son côté, Grace Davie prête une attention soutenue aux évolutions religieuses récentes opposant une Europe où la territorialisation du religieux demeure importante à la flexibilité du modèle congrégationaliste américain. Selon elle, la sécularisation ne peut être mesurée par les niveaux de pratique, car même si ceux-ci sont beaucoup plus faibles en Europe, les liens étroits entre les églises et l'État amènent à les considérer comme des services publics et à les maintenir dans l'espace public. Au final, Hugh McLeod plaide pour une histoire commune du monde nord-atlantique où l'évolution religieuse est très semblable, malgré des différences nationales ou régionales. Pour lui, ce n'est que dans les années 1970 qu'apparaît le clivage entre « une Amérique plus religieuse et une Europe plus séculière "; mais là encore, la nuance est nécessaire et par exemple le catholicisme populaire lui paraît aussi vivant en Europe qu'aux États-Unis, même si sa dynamique peut être entravée par l'anticléricalisme de certains contextes.

4 Toutefois, David Hempton achève ce volume en mettant en garde contre le risque de se borner à mettre en exergue "de petites différences» au cours du temps, car cela pousse à mettre l'accent plus sur les continuités que sur le changement et réduit considérablement l'impact de périodes significatives de différenciation entre les deux côtes de l'Atlantique. De quoi poursuivre le débat ré-ouvert par cet ouvrage stimulant, 
lecture incontournable pour qui souhaite renouveler les interrogations sur les métarécits de la sécularisation au travers du dialogue interdisciplinaire. 